\title{
Understanding Beliefs, Knowledge, and Practices of Mothers in the Dominican Republic Related to Feeding Infants and Young Children
}

\author{
Lynn M. Babington \\ Fairfield University, Ibabington@fairfield.edu \\ Follow this and additional works at: https://digitalcommons.fairfield.edu/nursing-facultypubs \\ Copyright 2006 Springer Verlag \\ NOTICE: this is the author's version of a work that was accepted for publication in Hispanic \\ Health Care International. Changes resulting from the publishing process, such as peer review, \\ editing, corrections, structural formatting, and other quality control mechanisms may not be \\ reflected in this document. Changes may have been made to this work since it was submitted \\ for publication. A definitive version was subsequently published in Hispanic Health Care \\ International, 4(3), 2006 available at www.springerlink.com.
}

\section{Peer Reviewed}

\section{Repository Citation}

Babington, Lynn M., "Understanding Beliefs, Knowledge, and Practices of Mothers in the Dominican Republic Related to Feeding Infants and Young Children" (2006). Nursing and Health Studies Faculty Publications. 15.

https://digitalcommons.fairfield.edu/nursing-facultypubs/15

\section{Published Citation}

Babington, L. (2006). Understanding Beliefs, Knowledge, and Practices of Mothers in the Dominican Republic Related to Feeding Infants and Young Children. Hispanic Health Care International, 4(3), 153-158.

This item has been accepted for inclusion in DigitalCommons@Fairfield by an authorized administrator of DigitalCommons@Fairfield. It is brought to you by DigitalCommons@Fairfield with permission from the rightsholder(s) and is protected by copyright and/or related rights. You are free to use this item in any way that is permitted by the copyright and related rights legislation that applies to your use. For other uses, you need to obtain permission from the rights-holder(s) directly, unless additional rights are indicated by a Creative Commons license in the record and/or on the work itself. For more information, please contact digitalcommons@fairfield.edu. 
Running head: Dominican Practices related to Feeding Infants and Children

Understanding Beliefs, Knowledge \& Practices of Mothers in the Dominican Republic Related to Feeding Infants and Young Children

\author{
Lynn M. Babington, PhD, RN \\ Associate Professor \\ Northeastern University \\ Boston, MA
}

Corresponding Author: $\quad$ Lynn M. Babington, PhD, RN

401B Robinson Hall

Northeastern University

Boston, MA 02115

1.babington@neu.edu

Funding Sources: This study was funded in part by a grant from Northeastern University, Boston, MA

Number of Words: 3,849

Number of Tables/Figures: 0

Key Words: Dominican Republic, Child Feeding Practices, Infants and Children 
Understanding Beliefs, Knowledge \& Practices of Mothers in the Dominican Republic Related to Feeding Infants and Young Children

Abstract
Background: Obesity in children has reached epidemic proportions in the United States where an estimated $15 \%$ of children are obese. Perhaps even more troubling is the finding that childhood obesity is correlated strongly with obesity in adulthood and is increasingly observed in younger age groups and immigrant children. Parents have a major influence on the weight of children and are therefore an obvious initial focus for education and support on healthy feeding practices. Nurses are in a unique position to take the lead in helping parents develop healthy child feeding practices.

Objectives: The purpose of this research was to understand the feeding practices, knowledge and nutritional beliefs of mothers with young children living in the Dominican Republic (DR). Methods: A focus group provided qualitative data for this exploratory, descriptive study. Results: The study resulted in a description of how mothers in the DR feed their children and on their beliefs about the health implications of child feeding practices.

Discussion: Findings from this study help to increase understanding of feeding practices of children in the DR. This knowledge can be used by nurses to develop culturally appropriate interventions for immigrants from the DR aimed at preventing childhood obesity. Interventions that consider the effects of acculturation will be more effective when targeted to parents of young children than interventions focused on treatment of obesity in later years.

Discussion: Key Words: Dominican Republic, Child Feeding Practices, Infants and Children 
Understanding Beliefs, Knowledge \& Practices of Mothers in the Dominican Republic Related to Feeding Infants and Young Children

\section{Background}

\section{Childhood Obesity and Immigrant Children}

Obesity in children has reached epidemic proportions in the United States where an estimated $15 \%$ of children are obese (Gielen \& Hambrecht, 2004). The immediate and long term physical and psychological ramifications of obesity in children is staggering (Myers \& Vargus, 2000; Strauss \& Pollack, 2001; Vaughn, 2005). Perhaps even more troubling is the finding that obesity is increasingly observed in younger age groups and immigrant children and is correlated strongly with obesity in adulthood. Findings from the National Health and Nutrition Examination Survey from 1999 to 2002 found approximately 1 in 5 children ages 2-5 are obese or at risk for obesity (Hedley, 2004).

The most recent US Census Bureau data estimate that 28 million foreign-born persons reside in the US, representing $10.4 \%$ of total population (US Census, 2001). Distribution of the US foreign-born population in 2000 included 52\% born in Latin America and the Caribbean and West Indian Islands (Malone, Baluja, Costanzo, \& Davis, 2003). Given the remarkable growth in the US immigrant population, the health status of racial/ethnic minorities has become an increasingly important public health issue. One in five children in the US today are from an immigrant family (Hernandes, 1999). Immigrants bring a rich cultural heritage with dramatically different beliefs, values, and customs, however, immigration to a new country can represent a substantial shift in a person's lifestyle and these changes can result in increasing risk for chronic diseases, such as obesity (Satia-About, 2002). In particular, adoption of the typical American diet, which is high in fat and sugar and low in fruits and vegetables, is of concern because this 
diet increases the risk of developing obesity. However, little has been published concerning the effects of immigrant acculturation and adaptation to American culture on the nutrition of children (Wang \& Tussing, 2004). Parents have a major influence on the weight of infants and children and therefore represent an obvious target for education and support on healthy feeding practices. Nurses are in a unique position to take the lead in helping parents develop healthy child feeding practices.

\section{Child Feeding Practices}

Parents, particularly mothers, play a critical role in preventing childhood obesity and are the agents of change in treatment of childhood obesity. Not only do parents' control the food young children eat, they also directly determine children's physical and social environment and indirectly influence behaviors, habits and attitudes through the socialization process (Ritchies, Welk, Styne, Gersteir, \& Crawford, 2005). During the first years of life, children learn an enormous amount about food and eating in the family context and are shaped by parents' own food preferences and selections, which in are a large part influenced by the cultural context (Birch, 1992; Stang, 2006). Birch and colleagues developed a model of child eating behaviors based on extensive research and learned that children under the age of five actually have the capacity to regulate energy intake when they are provided with a variety of food choices, do not have any foods restricted, and parental modeling of healthy eating takes place (Birch \& Davidson, 2001; Birch \& Fisher, 2000). Horodynski and colleagues used Birch's conceptual model to develop and pilot test a nursing intervention that supports healthy eating practices with rural, white, low-income families (Arndt \& Horodynski, 2004; Horodynski, Hoerr \& Coleman, 2004; Horodynski \& Stommel, 2005). Efficacy of intervention studies such as this one need to 
be tested with different populations, and may need modifications to achieve maximal efficiency for minority and immigrant families.

The study reported here is part of a larger program of research aimed at developing and testing a culturally and linguistically appropriate educational intervention for immigrant mothers to prevent childhood obesity. The first step in this research program was to gain understanding of feeding practices for infants and children and maternal knowledge and beliefs regarding the causes and health implications of obesity in mothers in the DR. This study will be followed by a replication in an urban area in the Northeastern part of the US with a group of mothers who immigrated from the DR.

\section{Specific Aims}

The purpose of this research was to expand knowledge regarding feeding practices and nutritional beliefs of mothers living in the Dominican Republic. This study, using focus group methodology, identified Dominican mothers' views related to the introduction of food to infants and feeding practices for young children along with knowledge and beliefs related to the causes and health implications of childhood obesity.

The research questions for this study included:

1. What are the feeding practices for infants and young children used by Dominican mothers?

2. What do Dominican mothers know about healthy size and weight and ideal diet for young children?

3. What do Dominican mothers know about the causes and health implications of childhood obesity? 
Methods

\section{Design and Settings}

Little is known about Dominican mothers' knowledge and beliefs regarding childhood obesity and its health implications or infant and child feeding patterns (Bloor, Frankland, Thomas \& Roson, 2001). Qualitative methods were used in this exploratory, descriptive study. A focus group, using participatory principles, was conducted with a group of mothers in the DR to collect data about their feeding practices for infants and young children along with their knowledge and beliefs related to healthy weight for children and the health implications of obesity. Focus groups serve as a useful starting point for exploratory research because they provide a means for determining how participants think and the ways in which they communicate (Bloor et al., 2001). The setting for data collection was a small city (population 40,000) in the western frontier area of the DR, Las Matas de Farfan. The study took place during one of the annual trips that the author participates in as a volunteer sponsored by Intercultural Nursing Inc. ${ }^{1}$ During the last 8 years of participating in these annual trips to the same area in the DR, the author has gained insight and understanding of the Dominican culture. IRB approval for the study was obtained through Northeastern University.

\section{Procedure}

Participants were recruited by word of mouth during mobile health clinics conducted in May, 2005, in Las Matas de Farfan. A Spanish interpreter and the principal investigator invited potential participants to learn more about the purpose of the focus group and how the session would be conducted. The principal investigator (through an interpreter) described the purpose of the study, how the study would be conducted and the confidentiality inherent in the process.

\footnotetext{
${ }^{1}$ Volunteer nursing organization delivering sustainable health care in impoverished rural areas of the Dominican Republic
} 
Additionally, participants were told that they did not have to answer any of the questions if they felt uncomfortable. Participation was voluntary. Participants also received a Spanish-language consent form describing the study.

Participants joined in a 45-minute focus group session moderated by the PI through an interpreter (Spanish). This session took place in a community setting. Participants were asked to provide basic demographic data. Forms were available in Spanish and the PI and interpreter assisted group participants who could not read or write. Names were not collected from focus group participants.

A semi-structured set of questions was used to ensure that specific issues were examined while allowing a certain level of spontaneity for participants to expand the discussion topics. The session was audio tape-recorded. When the session was complete, participants received a gift bag with personal care items for themselves and their babies.

\section{Sample}

The cohort for this study was a convenience sample of 10 mothers ages 16-45 years, (mean age $=25)$ with at least one child $(25$ children altogether and 2 of the women were pregnant). Two women reported being single, two were separated and 6 were married. One woman worked at a pharmacy and the rest did not work outside the home. The highest educational level attained was as follows: one had attended university (did not graduate), two graduated from secondary school, one completed $8^{\text {th }}$ grade, three completed $6^{\text {th }}$ grade, 2 completed $4^{\text {th }}$ grade, and one had never attended school. When asked how well they spoke and/or understood English, two said "a little", and the other 8 answered "not at all". The estimated yearly income for the entire family was reported by all 10 participants as less than 28,500 pesos (\$868 US dollars). 


\section{Data Analysis}

Data from the focus group were generated from field notes and audiotapes. The translator transcribed the audiotapes verbatim and data were reviewed by the PI for completeness and accuracy. A modified constant comparative method of analysis was used (Denzin \& Lincoln, 2000; Lincoln \& Guba, 1985). Transcribed data were systematically analyzed, organized and coded according to the specific aims of the study.

\section{Findings}

\section{Feeding Practices for Infants and Young Children}

All of the women who participated in the focus group indicated that they breast fed their babies from birth to a minimum of 6 months and most until one year of age. "We all breast feed in the DR. That is why our babies are so healthy." Formula is expensive and rarely available in the DR, although one woman stated, "In the capital (Santo Domingo), if you have your baby in the hospital, you get lots of formula to take home." There was a lengthy discussion about how the women learn to breast feed. Most of the women indicated that their mothers, sisters, and aunts showed them how to breast feed their babies. This comment led into a discussion about the breast feeding clinic in the public hospital in Las Matas de Farfan. "In order to register your child's birth, you have to have the form signed by the breastfeeding clinic. They also give you infant liquid vitamins for the baby's first 3 months." Several other women supported these comments and discussed what a "waste of time it is to have to wait in line to see the breast feeding person just to register your child, since we already know how to breast feed and everyone does it." The group unanimously agreed that they gave the vitamins to their newborns. When they run out of vitamins from the breast feeding clinic, they purchased them from the pharmacist. "Doctors and pharmacists say that babies need vitamins until they are a year old." 
There were several comments by the older two participants (aged 32 and 45) related to the negative aspects of breast feeding, "After having a couple of kids and breast feeding for so many years, your breasts start to sag and it's bad for them." When asked whether that influenced their decision to breast feed, they indicated that it did not, since they had few other options and lacked money to purchase formula.

The next area of discussion centered on the introduction of foods to babies. The women all spoke about tea being given in a bottle to babies around 6 months old. "We feed babies weak tea, usually green leaves, to help their stomachs and sometimes they are thirsty." They also described giving 6-month-old babies "a little bit of the water that beans are cooked in." This water is given in a bottle. When asked what kind of water the beans are prepared in, the women said, "There are no spices or fat in the water." Bottles are washed in hot water, but not sterilized. "If we can afford to buy baby cereal, we give it to them around 5-6 months old." Most of the women indicated that they rarely had the money to purchase cereal. Once babies are 5-6 months old, it is typical to feed them "smashed rice with a little bit of bean juice." The next food typically introduced is bananas, smashed with a little milk, followed by mangos, and watermelon. "After one year of age, babies get cow's milk, or goat's milk, and tea and maybe a little bit of smashed rice with the juice from beans." Children are not fed greasy or fatty foods until they are around three years old. "Children don't eat much meat since it is so greasy." Other foods fed to children under three include vegetables, such as yucca, eggplant, and okra. Bread is also given to young children. When asked about "sweets" the participants said, "We don't eat many sweets, but if it is a party, everyone gets a piece of cake." When asked how young the children were when they ate cake, the general response ranged from 2-4 years old. Knowledge About Healthy Size and Weight and Ideal Diet for Young Children 
Consensus of the group was that children are healthy if they are "not fat" and "got lots of exercise running around all day." None of the mothers ever weighed their children and when asked whether children were weighed when they went to the doctor or received immunizations, the response was that they were not. It was observed by the PI that there were no overweight and/or obese mothers in the focus group. In fact, in the experience of the PI, there are few overweight and no obese women or children living in this area of the DR.

Children older than three consume the same diet as their parents. They typically eat hot cereal, cooked with milk, for breakfast. The main meal of the day, eaten in the early afternoon, consists of rice and beans cooked with garlic and spices, and stewed vegetables. Two or three times a week, meat, chicken or pork and rarely beef may also be eaten. The meat is typically fried in cooking oil. In the evening, a snack of very salty cheese, fruit and tea may be eaten. When asked whether children drink milk or eat eggs, the response was, "we might have eggs once a week for supper, but they are very expensive and unless you have your own chickens, we don't eat many eggs." Milk is given to all children if they are in school. "Most children younger than 10 might have one glass of milk everyday."

\section{Knowledge About the Causes and Health Implications of Childhood Obesity}

When asked about some of the problems children have if they are overweight or obese, participants indicated that asthma was a problem for overweight children. The following quotes describe other health concerns discussed by the group. "If kids are too fat, they can't play sports and are left behind." "Fat kids have trouble running, and it hurts their heart." "They might have a stroke when they get older." There were no other specific health concerns or social problems discussed by the group. 
A lengthy discussion among the participants on why their children were healthier than children in the United States ensued. "Dominicans are healthier because of the food they cook. It tastes better, is juicer, and we eat less food. Americans eat too much food." "Also, we walk everywhere. Our kids run around all day long and American kids watch too much TV." None of the group participants had ever been to the United States, however all ten women had a relative, neighbor, or friend who had lived in the US for some period of time. In addition to learning about the US diet from friends and relatives, they indicated that they see lots of advertisements on TV for different kinds of food not available in the DR. "We don't have some of the snacky food that we see on TV. We also don't have McDonald's and hamburger places. These are bad places to eat!"

The discussion continued about how difficult it is for Dominicans moving to the US to continue to eat healthy foods. "People in the US are too busy and don't cook." "It is so easy and cheap to buy food that isn't healthy and makes you fat."

\section{Limitations}

The convenience, non-probability sample participating in this study was small and does not represent the broader population in the DR. Las Matas de Farfan is a relatively small city (40,000 people) surrounded by poor, rural campos (villages). The participants in this focus group were all poor and relatively uneducated and may not represent the views of most rural Dominican mothers. It is the experience of the PI, however, that the beliefs and practices discussed in the focus group are typical for many people in the rural areas of the DR. The practices described by focus group members may be quite different than the experience of women living in large cities in the DR (Santo Domingo and Santiago) because the lifestyle may vary, particularly for families who have more resources and different food items available to 
them. However, the findings from this study are a first step in understanding Dominican feeding practices and mothers' knowledge and beliefs related to nutrition for children and the health effects of childhood obesity.

\section{Discussion and Implications}

The women who participated in this focus group all breast fed their babies with the belief that breast milk is better for infants than formula. Cereal, fruits and vegetables are the main diet for children under three years old. Typically, "fast foods" and snack foods are not readily available and therefore rarely consumed. Obesity was viewed as a health risk for children. These mothers were practicing many healthy feeding behaviors, such as breastfeeding and limiting fats and sweets for young children, and they recognized their importance in promoting the health of children. They also recognized the challenges of maintaining a healthy diet in the US. To provide appropriate education and support to new mothers, it is critical that nurses learn about cultural traditions and beliefs surrounding child feeding practices.

Results from this study will be compared to results from an identical study that will be conducted with mothers who have recently immigrated to the US from the DR. Comparisons will be made between feeding practices, beliefs and knowledge about nutrition and ideal weight for young children between these two groups. These findings will help to increase understanding of the process of acculturation and its influence on knowledge and beliefs related to childhood nutrition and lay a foundation for understanding the process of acculturation on feeding practices. The primary goal of this research program is to develop a culturally and linguistically appropriate intervention that considers the effects of acculturation and is aimed at prevention of childhood obesity. Findings from this study on the feeding practices of mothers in the DR will help to build an intervention for immigrant mothers that capitalizes and supports culturally 
relevant child feeding practices. Early culturally based interventions are particularly appropriate with new immigrants as they acculturate into American society. In addition to developing and testing an intervention for the prevention of childhood obesity, the findings from this study will be useful for nurses who work with immigrant mothers and inform their teaching regarding healthy feeding practices for infants and children. Intervening with prospective parents before children are born and when their children are very young will be more effective than treatment for obesity in later years. 


\section{References}

Arndt, J.J., Horodynski, M. A., (2004). Theory of dependent-care in research with parents of toddlers: the NEAT project. Nursing Science Quarterly, 17(4), 345-350.

Birch, L.L. (1992). Children's preferences for high-fat foods. Nutrition Review, 50, 249-255.

Birch, L.L. \& Davidson. K.K. (2001). Family environmental factors influencing the developing behavioral controls of food intake and childhood overweight. Pediatric Clinics of North America, 48(4), 893-907.

Birch, L.L., \& Fisher, J.O. (2000). Mothers' child-feeding practices influence daughters' eating and weight. American Journal of Clinical Nutrition, 71, 1054-1061.

Bloor, M., Frankland, J., Thomas, M., \& Roson, K. (2001). Focus Groups in Social Research. Thousand Oaks, CA: Sage.

Denzin, N.K., \& Lincoln, Y. (2000). Handbook of Qualitative Research. Thousand Oaks, CA: Sage.

Gielen, S., \& Hambrecht, R. (2004). The childhood obesity epidemic. Circulation, 109(16), 1911-1913.

Hedely, A.A. (2004). Prevalence of overweight and obesity among US children, adolescents, and adults, 1999-2002. Journal of the American Medical Association, 291(23), 2847-50.

Hernandes, D.J.(1999).Children of Immigrants: Health, Adjustment, and Public Assistance, 1-18.

Horodynski, M.A., Hoerr, S., \& Coleman, G. (2004). Nutrition education aimed at toddlers: A pilot program for rural, low-income families. Family Community Health, 27(2), 103-113.

Horodynski, M.A., \& Stommel, M. (2005). Nutrition education aimed at toddlers: an intervention study. Pediatric Nursing, 31(5), 367-372.

Lincoln, Y., \& Guba, E.G. (1985). Naturalistic Inquiry. Newbury Park, CA: Sage. 
Malone, N., Baluja, K.F., Costanzo, J.M., \& Davis, C.J. The Foreign-Born Population 2000:

Census 2000 Brief, US Census 2000.US Census Bureau, Population Division, Ethnic and Hispanic Statistics Branch. US foreign-born population 2000. Available at http://factfinder.census.gov/servlet/SAFFFacts?_event=\&geo_id=01000US\&_geoContex $\underline{\mathrm{t}=01000 U S \& \_s t r e e t=\& \_ \text {county }=\& \_ \text {city Town }=\& \_ \text {state }=\& \text { zip }=\& \_l a n g=e n \& \_s s e=0 n \& A}$

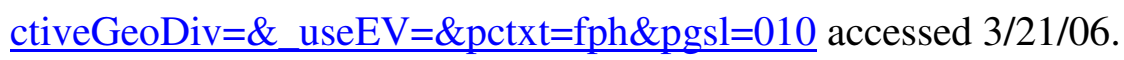

Myers, S., \& Vargus, Z. (2000). Parental perceptions of the preschool obese child. Pediatric Nursing, 26(1), 23-30.

Ritchies, L.,Welk, G., Styne, D., Gersteir, D., \& Crawford, P.B. (2005). Family environment and pediatric overweight: what is a parent to do? Journal of the American Dietetic Association, 105, S70-79.

Satia-About, A, J. (2002). Dietary acculturation: application to nutrition research and dieteticsperspective in practice. Journal of the American Dietetic Association, 102(8), 1105-1118.

Stang, J. (2006). Improving the eating patterns of infants and toddlers. Journal of the American Dietetic Association, 106(1), S7-S9.

Strauss, R.S. \& Pollack, H.A. (2001).Epidemic increase in childhood overweight. Journal of the American Medical Association, 286, 2845-2848.

U.S. Census, Profile of the foreign-born population n the U.S. (2000). in U.S. Census. 2001, U.S. Department of Commerce: Washington DC. http://factfinder.sensus.gov/serlet/SAFFIteratedFacts? Accessed 3/16/06.

Vaughn, K. (2005). A call to pediatric nurse practitioners in battling the childhood obesity epidemic. Pediatric Nursing, 31(4), 343-344. 
Wang, Y., \& Tussing, L. (2004). Culturally appropriate approaches are needed to reduce ethnic disparity in childhood obesity. Journal of the American Dietetic Association, 104(11), 1664-1666. 